\title{
Mockery and Morality in Popular Cultural Representations of the White, Working Class
}

\author{
by Jayne Raisborough and Matt Adams \\ University of Brighton
}

\author{
Sociological Research Online 13(6)2 \\ <http://www.socresonline.org.uk/13/6/2.html> \\ doi:10.5153/sro. 1814
}

Received: 1 Feb 2008 Accepted: 13 Oct 2008 Published: 30 Nov 2008

\begin{abstract}
We draw on 'new' class analysis to argue that mockery frames many cultural representations of class and move to consider how it operates within the processes of class distinction. Influenced by theories of disparagement humour, we explore how mockery creates spaces of enunciation, which serve, when inhabited by the middle class, particular articulations of distinction from the white, working class. From there we argue that these spaces, often presented as those of humour and fun, simultaneously generate for the middle class a certain distancing from those articulations. The plays of articulation and distancing, we suggest, allow a more palatable, morally sensitive form of distinction-work for the middle-class subject than can be offered by blunt expressions of disgust currently argued by some 'new' class theorising. We will claim that mockery offers a certain strategic orientation to class and to distinction work before finishing with a detailed reading of two Neds comic strips to illustrate what aspects of perceived white, working class lives are deemed appropriate for these functions of mockery. The Neds, are the latest comic-strip family launched by the publishers of children's comics The Beano and The Dandy, D C Thomson and Co Ltd.
\end{abstract}

\section{Keywords: Chav, Children's Comics, Cultural Representations, Disgust, Distinction, Humour, Middle Class, Ned, Ridicule, Working Class}

\section{Introduction}

1.1 Recent class analysis, drawing to different degrees on Bourdieu's emphasis on processes of distinction (1984), has focused both on the targets of class-oriented ridicule and its consequences for working-class people (McRobbie 2004; Skeggs 1997, 2004; Tyler 2006), and on the potential symbolic 'uses' of the white working class as 'other' for sections of the middle and 'respectable' working class (Reay et al. 2007; Skeggs 1997). However, in terms of the emotional specifics involved, recent work has tended to emphasise disgust as a mechanism of class distinction; mockery itself has escaped specific attention. In an attempt to contribute to contemporary class analysis, we explore how and why mockery operates to present the perceived lifestyles of sections of the white working class. This project forms one aspect of our broader enquiry into the relationships between cultural representation, class, consumption and identity; itself underpinned by the belief that it is only by exploring the particular ways in which class distinction gets done that we get a sense of how class categories come to be concretised and problematised (Adams and Raisborough 2008). Our aim is to develop a more subtle appreciation of the distinction work of class fractions - one that speaks to a complex matrix of anxiety and uncertainty over status, unease at privilege, acquisitiveness, liberal tolerance and civic values (Reay et al. 2007; Sayer 2002; Vincent and Ball 2007). We are, then, focusing on mockery as a means of expanding our understanding of classed distinction work.

1.2 We draw on recent class analysis; much of it influenced by the work of Bourdieu, to argue that mockery frames many cultural representations of class and move to consider how it operates within the processes of class distinction. Influenced by theories of disparagement humour, we explore how mockery creates spaces of enunciation, which serve particular articulations of distinction from the white, working class. From there we argue that these spaces, often presented as those of humour and fun, simultaneously generate a certain distancing from those articulations. The plays of articulation and distancing, we suggest, allow a more palatable, morally sensitive form of distinction-work for normative subjectivity than can be offered by blunt expressions of disgust. We will claim that mockery offers a certain 
strategic orientation to class and to distinction work. In the second part of this paper we turn to a comedic representation of white working class in a popular children's comic. We do so not in terms of a detailed content analysis but as a means of illustrating some of the particular forms class representation are taking. Our first task, however, is to outline the importance of cultural representation to the contemporary theorisation of class.

\section{The Importance of Cultural Representation to Class Analysis}

2.1 In the early 1990s the conditions of late modernity were seen to be heralding an era of 'individualisation'. These conditions are produced through processes of radical social change, including forces of detraditionalisation, time-space distanciation and cultural disembedding, as identified by Giddens (1991; 1994). The consequence, Giddens argues, is that the self 'becomes a reflexive project' (1991: 32), involving the strategic adoption of lifestyle options' related to a planned 'trajectory', all geared to maintaining a meaningful biographical narrative (Giddens 1991: 243-244). For Beck and others, individual agency or more accurately 'individualization' takes centre stage in late modernity; the exercise of choice becomes central to meaningful identities, replacing class, and what he describes as obsolete or 'zombie' concepts which once provided the cardinal points for identity (Beck and Willms 2004). Despite these challenges to the conceptual relevance of class, a now familiar refrain claims that class is re-materialising in and through the conditions of late modernity (Brannen and Nilsen 2005; Nayak 2006;Skeggs 2005; Lawler 2005; Savage 2003).

2.2 Significantly, recent sociological accounts of class draw upon the realisation that the economic moorings, of class, no longer always secure and reliable, are often strengthened by the circulation of social and cultural capitals. The process of valuing aspects of cultural life (such as lifestyle, self-presentation, consumption practices, language style) is a further means to assert distinction, recognition and distribute privilege, which in turn reproduces economic privilege. In Crompton's pluralistic incorporation of 'materialist' and 'culturalist' accounts of the relationship between social class and the family, she asserts that

in order to understand processes of reproduction and differentiation by class, social classes cannot be adequately conceptualised as economic or material categories in isolation, but are also characterised by cultural and normative practices that themselves serve to maintain differentiation from other classes and to reproduce class inequalities (Crompton 2006: 662).

2.3 While there is a danger in sticking too closely to a simplistic and tautological reading of Bourdieu to claim that cultural practices reinforce cultural practices, it is important to acknowledge that representing 'others' is a cultural practice that can have material, social, cultural and personal consequences for those who end up as in- and out-groups. The most useful aspect of 'culturalist' accounts of class in this context is the recognition that these consequences may also inscribe and reinforce class hierarchies in terms of access to resources which include social recognition. Thus via her own analysis of cultural forms, Skeggs suggests that 'class is insinuated in the intimate making of self and culture' more than ever, 'leaking beyond the traditional measures of classification' (Skeggs 2005: 969). She argues for the need 'to move beyond (but still with) the economic... into understanding value more generally to understand how class is made through cultural values premised on morality, embodied in personhood and realized (or not) as a property value in symbolic systems of exchange' (2005: 969).

2.4 The reason given for the expansion of the cultural realm in the making of classed selves tends to revolve around claims of an increased initial proximity of previously distinct social classes. Lawler, for example, claims contemporary representations of class stem from a middle class requirement to establish distance from those that may otherwise become dangerously indistinguishable in spatial, cultural and economic terms: 'when legal barriers between classes get broken down, as in democracy, social hierarchy must be maintained in other ways... [working class people] must be 'pushed away' - expelled from a normative and normalized middle-classness' (2005: 440). Sayer similarly claims that emotionally motivated boundary work is 'particularly strong in groups that are anxious about their position' in relation to those 'above' and 'below' (Sayer 2005: 953). ${ }^{1]}$ Skeggs also identifies a crisis in middle-class authority and security (968), as the starting point for the ubiquitious interpenetration of class, culture and self, originating in:

the increased proximity of different groups in everyday life (via public movement, transport, omnivorous taste, etc.).... it is not always the dangerous other that threatens, but the proximate stranger who is not as easily identifiable, so she is made so. She is therefore represented to such an extent that nobody could fail to recognize her and her lack of moral value. She is transformed into a recognizable figure: the figure of the constitutive moral limit in proximity (970)

It is this manufacture of the particular into universal norms of conduct and personal worth that forms the prevailing socio-cultural context, in which we all become obliged to negotiate our identities in prescriptions of what one 'ought' to do (Rosin 1997).

2.5 Of course, the relationship between change, anxiety and the construction of 'specific types' has a long history (Domosh 2001; Hayward and Yar 2006; Welshman 2006). Domosh's (2001) account of 1860s New York observed how, as shopping surfaced as a leisure pursuit for all, the middle classes could not be sure of the socioeconomic status of those they saw and met everyday' (2001: 575). Victorian texts written by the genteel classes used 'moral coding' to identify a disrespectable 'type', as means of securing class lines. The result was the 'New York Woman', identified by her vulgarity, frivolous consumption, and neglect of hearth and family. The 'moral' texts produced a certain 'urban anthropology' that encouraged 'spotting' the New York Woman and marking out her territories (Domosh 2001: 575). Such texts as neatly tutored the bourgeois in the dictates of their own respectability as they sketched the wayward life of the Other. The need to make recognisable the other who comes too near and the utilisation of taste to maintain distance 
under conditions of proximity has strong parallels, we argue, with contemporary representations of the lumpish youthful proletariat in shopping malls distinguishable by their clothes and jewellery' (McDowell 2006: 837).

2.6 What is argued to be unique is that the normative aesthetic of taste takes places more explicitly 'within the space of relaxation and enjoyment provided by the media and entertainment' (McRobbie 2004: 104). It is in specific cultural representations that we can locate the 'awful mocking discourse' (McDowell 2006:837) directed at the white-working class. The sheer scale of class ridicule is only possible, argues McRobbie (McRobbie 2004: 100), in 'post- politically-correct times' where assertions of irony serve to shift what would otherwise be explicit denigration to harmless 'good fun'. These concerns call us to question why mockery and ridicule are employed to the service of distinction work in the ways we are currently witnessing in our daily media consumption. We will go on to discuss the role of disgust in contemporary distinction work, before addressing McRobbie's observations of how mockery accompanies the conferment of taste in reality shows. Although finally we focus on a very different popular cultural form, McRobbie's analysis has a broader relevance in relation to the operation of mockery.

\section{Distinction and Disgust}

3.1 If we accept claims that 'middle class self-interest is couched as a universal good' that defines 'the normal', indeed, the social (Savage 2003:536), it is then incumbent on the social scientist to engage in 'a kind of forensic, detective work' that enables the 'normality of the middle class...to be carefully unpicked' across the sites of the everyday (Savage 2003:537). We are reminded of the political sensibility of this project by McDowell's observation of the connection between worth, citizenship, 'cultural mis-recognition and material inequalities' (McDowell 2006: 828). The forensic project is then, motivated to keep class in critical sight. This demands political awareness that the very things needed to signal worth are

inaccessible or difficult to access for some, yet deemed the naturalised properties of others (Skeggs 2004; Vincent and Ball 2007). It also, following Lawler (2005), requires attention to the dynamic nature of class, in particular the circulation of inequalities through cultural and symbolic domains while representing the individual as author of one's own fate.

3.2 Forensic work draws not uncritically on Bourdieu's account of taste and distinction (Savage 2003; Sayer 2005; Vincent and Ball 2007). The operations of taste allow an expression of normative distaste for working-class lifestyles. This is exemplified in the proliferation of the terms 'chav', 'ned' and 'white trash' (Hayward and Yar 2006; McRobbie 2004; Nayak 2006; Skeggs 2004) and various media representation of these 'types'. In consequence a certain section of the white, working class is identified as culturally distinct through their consumption and lifestyle, which purportedly reflect certain morally-reprehensible attitudes, and excess (Haylett 2001; McDowell 2006).

3.3 The symbolic violence operating within processes of distinction is not lost on Lawler (2005) and Tyler (2006) who identify the workings of middle-class disgust. Both draw on Miller's (1997) dissection of the workings of disgust to social hierarchies. For Miller, disgust may overlap with distaste and contempt for a lowly 'other', but is distinguishable because it is 'bound to metaphors of sensation' needing 'images of bad taste, foul smells, creepy touchings, ugly sights, bodily secretions and excretions' (1997: 218). This partly explains why many stereotypes tend to target bodily traits and any 'immoral' activities. There is more at work here than simply 'looking down' on the Other (Lawler 2005). The visceral nature of disgust produces recoil, a sense of horror at the thought or presence of the 'sick-making' taste of others (Bourdieu 1984: 56). Disgust as felt offers certain reassurances of the 'natural' and rightful status of one's own tastes (Bourdieu 1984).

\section{Failing the Taste Challenge}

4.1 Mockery has been identified as a form of 'disparagement humour', which 'denigrates, belittles or maligns an individual or social group' (Ford and Ferguson 2004: 79). It is argued to be a social resource mainly available to privileged groups (Cowan 2005; Sanders 2004), that works by communicating the parameters of shame and embarrassment as it simultaneously polices normative behaviour and beliefs through the ridicule of a selected 'other' (Billig 2005; Stott 2005). If, to paraphrase Bourdieu, taste serves as an 'ideal weapon' in boundary-marking, then disparagement and denigration seem unproblematic bedfellows. They are the means by which the Other can be 'pushed away' (Lawler 2005: 440; Tyler 2006).

4.2 McRobbie's (2004) contribution to critiques of television 'make-over' shows is to detail how mockery succeeds in establishing and maintaining class relations despite the show's intention to 'improve' and 'transform' its participants. Her critique of What Not to Wear [2] (WNTW) starts from the premise that 'makeover' shows are sites of public denigration of women 'of little or no taste' by women of 'recognisable taste' (McRobbie 2004: 99). Noting how expert-presenters use mockery as way of encouraging the participant to realise their lack, McRobbie observes 'sniggers', general teasing and 'giggles' of the presenters as they shame their participant to 'awareness'. It is through mockery that bodies are manipulated, privacy violated and clothes/appearance and problems are presented with a casual-comic flourish. That participants volunteer and react with humility and gratitude is indicative of the working-classes' 'feel for the game' that is to know 'instinctively and unconsciously' their place 'in regards to the experts' (McRobbie 2004:103).

4.3 Mockery is particularly explicit when the presenters have a physical distance from the participant. The formula of WTNW involves sending the participant out to apply her recent instruction of what she 'ought' to buy, while the presenters watch through CCTV. McRobbie notes the cruel, '1950s boarding school' (p.106) 'guffaws' of the presenters as they watch the participant hesitate and stutter in the face of a now morally loaded consumer choice. As the participant fails her taste challenge, the experts step in and with more 'supportive' mockery sweep her to the successful 'reveal' demanded by narrative causality. 
lifestyle proclamations. The intricate framework of appropriate taste that is the natural property of those born and habituated in to it (McRobbie 2004; Skeggs 2004) becomes the very context where the pretender provides entertainment-value through incongruity and the faux pas, both key comedic elements (Stott 2005). We would add, following from Domosh (2001) that such shows serve to help identify a 'type' and by marking out 'its' practices provide an indication of the material and symbolic resources and practices both to be avoided and to be embraced. They operate to attach moral stigma to those who are worst-off in class terms while moral superiority is attached to higher classes' (Reay et al. 2007:1049).

4.5 As McRobbie's concern was to outline the extent of mockery, she did not give space to an examination of mockery as a strategic orientation to the articulation and distribution of 'taste'. She does, however, provide us with a further point of intervention by stating that WTNW is presented as if ironic, as if 'it is not meant to be taken literally' (p.106). We share some of McRobbie's suspicion that irony/parody can mask the reproduction of the values it purports to satire (Davies 2005; Mitchell 2005): Tyler (2006) for example, is unconvinced that laughter at the chav is anything but means of 'expulsion'. However, it is the middle classes' position in respect to that act of expulsion that we want to examine further. We are interested here in the way mockery can function as certain ways of speaking distaste/ difference under conditions of proximity, while simultaneously forging some distance from those expressions and articulations. Savage $(2001,2003)$ and Sayer $(2005)$ can help elucidate the suggestion that a distance from the processes of distinction is possible even as they are exercised. Both, in different ways, note the workings of middleclass compassion, unease and ambivalence over privilege that might thread through what Lawler earlier described as the 'psychic' need to push the working class away.

\section{Why is Mockery Deployed in Class Boundary-Drawing?}

5.1 We feel mockery serves a particular function. Though not necessarily any less powerful, it befits an audience more consciously liberal, tolerant, and ironic, and perhaps polite (Valentine 1998), in its navigation through popular cultural forms than the expression of disgust suggests. Mockery may allow the middle class a more subtle and strategic orientation to the requirement of distinction. It is perhaps a means of 'doing' class under conditions of anxious proximity while disguising its intent (Mitchell 2005), and allowing the 'mocker' (distinction-worker) a palatable dissociation from what could otherwise be distasteful labours and expressions (explicit statements of disgust).

5.2 The workings of disparagement humour are deconstructed by Billig (2005), who argues that humour creates moments and spaces in which a suspension of social criticism is expected. The qualifier 'it's only a joke' is a prime example of the ways humour seems to lift itself beyond social reproach. 'Lifting' occurs through a series of non-threatening and playful cues (Ford and Ferguson 2004; Sanders 2004) that serve to remove the joke to a different interpretive register. Ford and Ferguson (2004: 81) envisage this as a 'switch' in mindset from 'usual serious' to 'levity'. In that moment of switch, we, as receivers of humour, are 'tacitly consenting' to the values portrayed in and through the disparaging humour and 'relax the usual 'critical sensitivities' to treat discrimination in a more 'light-hearted manner' (Ford and Ferguson 2004: 83). Lifting and our response to this are, as Billig (2005) argues, learnt forms of communicative behaviour that demand great skill. However, if 'lifting' invites us to a space of different interpretation, it is not always the case that we accept. Billig (2005) argues that laughter exists because of the possibility of non-laughter, that moment when the absence of laughter is most marked and the humour rejected. Our sense of what is acceptable and appropriate may dictate that moment. However, as humour 'changes the rules in a given context' (Ford and Ferguson 2004: 79) going against the preferred reading or ignoring the joke can, depending on the social context, be a source of embarrassment or unease, no matter how principled (Beaulieu 2007). The space created by humour and mockery is charged with relations of appropriateness - both in the telling/ presenting and in the receiving.

5.3 For us, the 'lifting' is not so much a re-location that is suggested by the metaphor of switching but rather a dislocation. For humour/mockery to have meaning, it must be firmly anchored in wider cultural representations (Billig 2005; Mitchell 2005), but these 'knowns' are stretched and disordered, or dislocated, through caricature, exaggeration and amplification in what Cowan (2005) calls the 'ridicule event'. The dislocating properties of humour impact upon the mocker (or in our case the producer, presenter or publisher) who is enabled some distance from the function of mockery even when it occurs. They can displace the responsibility of the 'joke' onto the receiver through the lifting devices detailed above and also significantly in the safe retreat, and relocation that the phrases 'it's only a joke' or 'harmless fun' provide. The joke is then a position of enunciation that does the work of distinction yet holds little accountability nor authorship. Mitchell (2005) has made a similar argument about the ways that television comedies effectively mask their careful construction of a rhetorical space from which to circulate conservative values, through assertions 'fun' and parody. To disagree, as Dobson (2006) suggests in his celebration of The Simpsons, is simply to 'not get the joke'.

5.4 The issue of accountability brings us to consider utterances of disgust in the work of 'expulsion' (Tyler 2006). The expression of disgust is a powerful boundary marker between psychosocial projections of what one is and what one is not. But it also carries with it potential baggage which might endanger other elements of a middle class project of selfhood - prudishness, unworldliness and fragility. Could the possible oscillation between dis/relocation enable one to speak disgust or distaste without necessarily identifying as one who is disgusted? Initially, this question challenges the claims we have made for distinction-work so far. That one is recognised as, say, disgusted is indicated by Bourdieu's taste classifies and it classifies the classifier' (Bourdieu 1984: 6): the politics of recognition are lodged in the fixing of the Other in ways that achieve recognition of one's own worth. However, the politics of recognition are too complex to be based on disgust alone. While there is an observable prevailing antagonism expressed in cultural representations of class (Tyler 2006), there is also a certain immorality to mocking and its association with bullying that make that act of expulsion through laughter unpleasant, impolite and even daring work for those protecting their own worth, differentiating it further from disgust. 
5.5 We need to consider too that those in normative positions may also be anxious about 'getting it right' themselves. McRobbie's (2004) critique of WNTW argued that such programmes provided a middle class audience with a confirmation of the positive value of their own practices and tastes but there may be a more complex viewing reception. 'Self-improvement' discourses of this type also work on those who may expect to be improved already: perhaps feeding into aforementioned anxieties about whether middle-class normativity is correctly being applied to the project of 'making up' one's self, and in the context of family life and one's children (Vincent and Ball 2007). Similarly, the existence of non-laughter (Billig 2005), the possibility that denigrating humour will not be appreciated or accepted indicates something of the risk in mocking/ joke-telling that depends on the assumption that some share a common stance (i.e. disgust) against a stated other. The possibility that that one can 'go too far' or that one can be inappropriate or cruel in mockery suggests that careful negotiations within classes are necessary to distinction-work. The inappropriate joke can run the risk of undermining one's belonging to the normative class position, of being seen to have 'poor' taste (Valentine 1998).

5.6 Another potentially important motivation for the use of mockery rests on a more nuanced understanding of the motivations of middle class distinction work more generally. Sayer's $(2002,2005)$ focus on morality and compassion allows him to claim that while boundary drawing still operates along class lines, it is not motivated on the whole by a starkly competitive desire to distinguish one's self from a 'lower order', but by a more complex middle-class intersubjective awareness of 'the existence of class inequalities', noted by Savage et al. (2001: 880), and by extension middle-class privilege (Sayer 2002). This awareness may reflect avowed unease and ambivalence about class differences:

There is a widespread sense in lay thought - sometimes articulated, but often only subconsciously felt - that class differences are at least in part unjust, insofar as individuals' position and life chances are a matter of luck, according to the accident of birth. Insofar as actors recognize this injustice - and it is hard for them not to - it prompts mixtures of guilt, resentment and defensiveness, and the balance of these feelings and the ways of handling them are likely to vary according to class position (Sayer 2002: 4.3)

5.7 It is this recognition that ambivalence, guilt and unease at 'natal privilege' can intersect with anxieties and disgust that make the movements of mockery ideal articulations of middle-class distinction-work. Dislocation in enunciation of distinction can be 'guilt-free' (Mitchell 2005) if attributed to 'known' attributes of the Other and disgust can be aired in such ways that can be denied if challenged and indeed if subject to reflection. 'It's only a joke' is not then, just a means of relief from class tensions or the confines of political correctness (Dobson 2006), but rather speaks to the ambivalence of marking out moral properties as middle-class, and at a general unease at expressing disgust/ distaste in the context of a liberal, individualist sensibility.

5.8 We end this first section aware that mockery and ridicule operate in ways that 'do' distinction work. We are critical of claims that mockery is 'harmless fun', but are reluctant to see mockery as solely generated from widely held middle-class disgust for the white, working-classes. Instead we suggest that mockery emerges as qualitatively distinct representation of class because it expresses tentative ambivalence and anxiety, unease and disgust. What is important about critical accounts of 'self-improvement' shows like WNTW in particular is what they can tell us about the 'uses' of mockery for its protagonists and its recipients. At a broad level, the underlying processes are similar to those utilised in the expression of disgust as identified by Lawler (2005) and others: poor taste is naturalised as an individual failing, a personal lack, which collective representation as 'neds' or 'white trash' present as an almost coincidental amalgamation of abject individuals. This presentation masks the normative work being along class lines to demark norms or the Other's lack. However, what we have argued here is use of mockery relieves those who 'get the joke' of the psychosocial burden of denigrating structurally disadvantaged others.

\section{A Comic Illustration}

6.1 Having considered the possible functions of mockery to the project of class distinction, it is appropriate here to illustrate our claims with an example of the forms that contemporary cultural representations of class take; what aspects of perceived working-class lives are deemed appropriate for mockery? In February 2007 D. C. Thomson and Co Ltd, the home of comics the Beano and The Dandy, launched the BeanoMax. Advertised as the 'big brother' to the weekly Beano, the monthly BeanoMax features familiar comic characters, celebrity interviews and longer stories as ways of appealing to a slighter older audience (9-13 years). Our attention is drawn to the BeanoMax because it is home to a relatively new comic-strip family The Neds who make guest appearances in the comic. Ned, his wife Nedette and their children, Asbo and Chavette are, as their names suggest, representations that draw heavily on prevailing stereotypes of white, working-class families and their assumed behaviours and values (abusive and 'work shy'). 


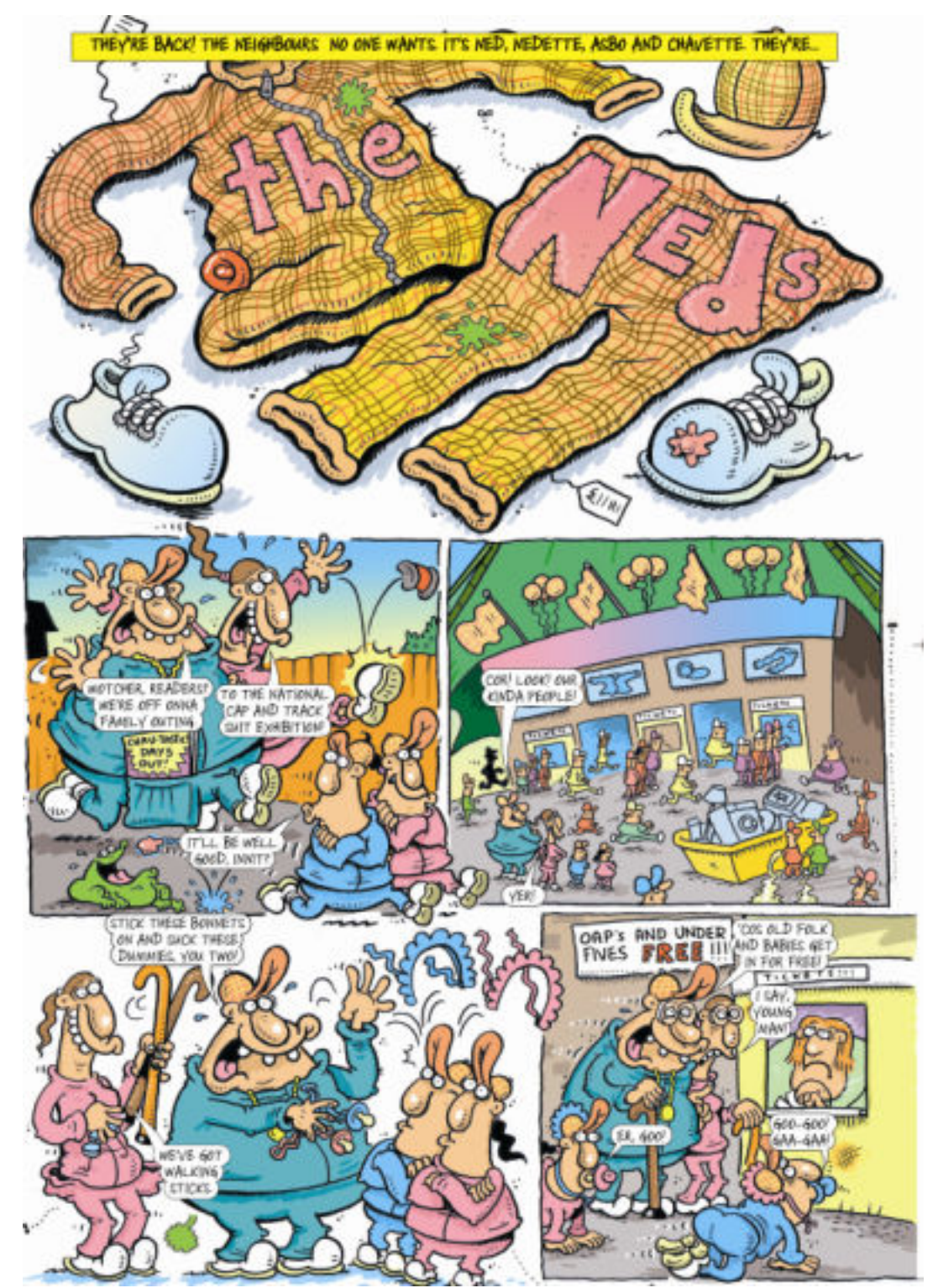

Figure 1. The Neds 1. (The Neds (C) D.C. Thompson \& Co. Ltd)

6.2 Most existing analyses of white working class stereotypes have focused on adult-oriented media and culture (e.g. Nayak 2006; McRobbie 2004). There is an emergent in interest in children's relationship to class (Sutton et al. 2007; Reay 2007, 2006). Although under researched, cultural material directed at children and young people is clearly an area of some importance. Accordingly we will turn our attention to a preferred reading of a comic strip. Comics also offer a useful site for this exploration because in order to be read quickly, they tend to reproduce prevailing stereotypes (McAllister et al. 2001; Synder 1997). Indeed a strip's success is largely dependent on its skill in anchoring its content to wider cultural registers; Landscapes, dress, gestures and behaviours of characters in the strip are drawn from images already circulating in the social imaginary. Such anchoring can be harnessed to illuminate the simplistic fantasies of stereotypes, and through defamiliarisation, provide a subversive reading (Synder 1997). However, generally mainstream children's comic-strips offer a relatively unambiguous 'closed' text with 'themes and values...especially explicit' (Carrier 2000; McAllister et al. 2001:4). Williams' (1994) assessment of the subversive nature of children's comics found little to challenge DiFazio's claim that 'comic books generally present values considered important in our society (cited in Williams 1994: 142). Dorfman and Mattelart (2006) remind us that it is adults who devise and write children's comics and McAllister et al. (2001) suggest certain middle-class hegemony within publishers and writers.

6.3 In terms of the deployment of mockery, McAllister et al (2001) argue that comics are often regarded as 'as insignificant 'funnies" (McAllister et al 2001: 4). This lifting to the funny, and removal of accountability, is enabled in the case of BeanoMax's Neds not just through the medium itself ('comic'), but also through the use of bright colours, exaggerated 'cartoon like' drawings, the sense of speed and movement, and general slap-stick antics. The Neds comic strip attracted criticism from the Scottish Parliament, dismayed that Scotland's working class should be presented through 'grotesque' and 'damaging' caricatures (Horne 2006). The publishers' responded by asserting their intention to create a certain topicality for their readers through 'harmless parody' and 'fun' (Horne 2006; Spencer 2006).

6.4 That the publishers defended The Neds as a 'harmless parody' alerts us to McRobbie's (2004:100) ironic observation that 'it is now possible, thank goodness, to laugh at less fortunate people once again'. She is not alone in noting a shift in comic representations. Law (2006) argues that Scottish sit-coms such as Rab.C. Nesbitt relied on 'sympathetically drawn characters. Living by their own codes, speaking in their own voices'. Yet, he notes now a 'hardening' of these representations into hateful caricatures of the white, working class. Likewise, McDowell (2006: 839) observes in popular culture repeated depictions of the urban 
poor as 'un-modern, anti-cosmopolitan, backward and worthless' (McDowell 2006: 839). While humour and comedy can be potentially subversive and insightful, Lockyer and Pickering (2008) remind us of the sociological importance of asking 'whether the humour kicks socially up or down' (p.812) - does it target the powerful or mock the vulnerable?

6.5 That the humour 'kicks down' is strongly suggested because hed' is a derogatory term for particular sections of the Scottish white working class. The etymology of the term is uncertain but there are strong parallels with the English term 'chav', 'trailer-trash' (USA) and 'bogan' (Australia), and their regional variants; 'pramface', 'schemie' and 'pikie' (Law 2006; McRobbie 2004). Though many of these categories may reflect important political and historical distinctions, all share the typology of 'primitive 'white trash' underclass' (Nayak 2006: 824). Law, for example, acknowledges the geographical specificity of terms in Scotland ('tinkies' and gadgies'), but he also suggests that the 'ned' is Scotland's own term 'for more general phenomena' (2006: 28); and considers both 'chav' and 'ned' as interchangeable 'local terms' for the 'most impoverished, reviled, humiliated and dominated sections of the working class' (2006: 29). Thus whilst we must remain alert to the cultural specifics of representations of the 'ned' our intention here is to consider it as an exemplar of derogatory popular representations of a subsection of the white working class more generally. [3]

6.6 Before we proceed, an important caveat is a reminder of the dangers of relying on unproven empirical claims about the relations between assumed middle class producers and a middle class readership. It is necessary to rely on an understanding of cultural production as a kaleidoscopic phenomenon, not reducible to a particular group or class, nor directed intentionally towards a particular outcome. Thus Skeggs (2004) says of the process of cultural production: 'representations have nothing to do with intentionality, but more about ignorance of the producers and their lack of knowledge about the cultures they represent' (97) or even a product of lazy and cheap media production, in which copying is deployed' (Skeggs 2005: 978). She reminds us that new (and old) representations of class are constantly 'being worked through' (98). However, it is significant that, intentional or not, repeated representations give us 'frameworks by which we mis/recognise and interpret others' (99).

6.7 These frameworks, as Joffe and Staerklé indicate, cannot simply serve discreet and prescriptive class interests, rather they provide resources for common sense thinking:

Mass media... play a major role in constructing common sense concerning outgroups by disseminating the representations on which lay people draw when forming representations of social problems such as criminality, poverty, deviance and illness. These phenomena tend to be constructed in terms of responsibility and blame and associated with social groups...They raise questions concerning who is dangerous and threatening, and who should be avoided (Joffe and Staerklé 2007: 402-3).

In terms of comic representations then, stereotypes are not simply wielded by one class in its war of distinction against another. However, there are patterns to cultural representations of class, which a 'preferred reading' can highlight. Epstein and Steinberg (1998) describe a preferred a reading as one which whilst alert to the possibility of multiple readings, focuses on repeated representations which, they argue, encode certain presumptions into media output. Preferred readings cannot of course claim to account for reader's reception, but they are useful initially mapping out the shape that stereotypes take before audience/reader interpretation.

\section{The Neds}

7.1 We now discuss two Neds comic-strips to consider the particular shapes that mockery takes when directed at the white working class. We offer these strips as telling cases, illustrative of comic representations of the ned and the chav more generally (e.g. Bok 2004; Pilrig and McGlinchy 2005; Stapleton 2007). The Neds make irregular appearances in BeanoMax, featuring as 'guest' or 'special' extras. We have focused on two of these appearances; The first 'Ned's History' (NH) was published in October 2007. The second story, The Family Outing (FO) was presented in the Beano Annual 2008, a publication which, at time of writing, sold approaching quarter of a million copies in the UK ( The Observer, 13 January 2008). To reiterate, we are focusing on preferred readings of these scripts, and make no claims about the readership or its class base. We would avoid assuming the readership are middle-class consumers bolstering their own cultural superiority: it is more likely a reflection and reproduction of certain and normative 'middle class values' which serve as reference point for the pervasive neo-liberal individualism of personal responsibility (e.g. Rose 1990).

7.2 The first story, Ned's History, shows Ned and Nedette using their home computer to 'search out our past for great Neds throughout history'. The panels then take us through various historical moments familiar to most British school children, in which neds have played a comic, but central role - the extinction of dinosaurs, the depiction of the Norman defeat of King Harold in the Bayeaux Tapestry, the French Revolution and the Second World War the great fire of London. The second story, The Family Outing follows the Neds on a family visit to the 'National Cap and Tracksuit Exhibition'. In a series of panels we are shown the Neds arriving and entering the exhibition, a full-page panel of the populated exhibition space and its various attractions, followed by Ned's 'test-drive' of a state-of the-art tracksuit with various 'special features'. Rather than work through the stories and panels chronologically, we have used a preferred reading to highlight the repeated nature of two sets of stereotype content which cut across both stories: 'productivity and sloth' and 'space/dirt'. Although a closer reading no doubt reveals a much greater variety of themes, these two were the most prevalent in our reading.

\section{Productivity and Sloth}

$\mathbf{8 . 1}$ It is argued that independence is a core marker of good citizenry. Within the operations of consumer 
capitalism and relational dynamics of responsibility and rights, independence is closely tied to financial security and gainful employment. Joffe and Staerklè similarly claim that 'Individualism is a core value in western culture' (Joffe and Staerklè 2007: 396). For these authors, a key component of individualism is self-control, which has itself become 'an organizing principle of personhood' (2007: 397). In taking a social representations approach which has many parallels with Bourdieu's emphasis on the pivotal role of distinction in the definition of self and other, Joffe and Staerklè argue that 'by associating outgroups with a paucity of self-control, dominant thinking transforms the ethos into an instrument of exclusion and derogation' (2007: 396). Interestingly, their account describes bodily excess and a lack of productivity as central stereotypes in representations of transgression. If 'productivity and paid labour are deemed the primary means to achieve self-control over destiny' (Joffe and Staerklè 2007: 408) and 'the fat person embodies loss of control and moral failing in terms of sloth and gluttony (Joffe and Staerklè 2007: 405). How do these constructions play in The Neds?

8.2 In the first panel of Ned's History, Ned interrupts Nedette's online Bingo (funded by her Job Seeker's Allowance) to search for 'great Neds throughout history'. The term 'jobseekers' is presented as a source of great amusement: Ned exclaims 'HAW-HAW! That always tickles me, that does', as they collapse with laughter. Their response to the phrase appears to indicate a knowing and deceitful 'playing of the system' that resounds in perennial moral panics around welfare fraud and state dependency. It also indicates a wilful lack of productivity, indeed, laziness and idleness are key motifs of popular representations of the chav and the ned (e.g. Nayak 2006), and is clearly reproduced in the Neds.

8.3 Ned's online tour then takes him through past incarnations of the Ned, through which various characteristics are stamped on the historical antecedents of the present-day Ned. In the first, obese 'cave Neds' litter the pristine prehistoric landscape, before their flatulence 'exstinks' the dinosaurs. Here laziness and indolence is read from the obese body; and unrestrained bodily excesses combine with a disregard for the environment to historically locate the disgusting, but in this context, 'funny' characteristics of the Ned. The next stop is the Great Fire of London, caused by Neds burning their chips. Ned's claim that 'chips is good for curing The Plague' clearly anchors the Neds to prevailing discourses that position individuals as (ir)responsible for levels of good nutritional practice and body-size. The next historical sees Neds with 'jobs', a fact noted with surprise by Ned: 'some Neds actually had JOBS!' Again, we are reminded of the normative laziness of the Neds. Even employed Neds however, reiterate their already established negative characteristics. An executioner Ned, again obese, eats the chewing gum from a severed head. The characteristics implied here, besides opportunistic greed, are multiple and possibly the lowest imputation of morals in either strip, breaking mores of hygiene, decency and respect, at the only moment Neds appear to meet the organizing principle of 'productivity'! 


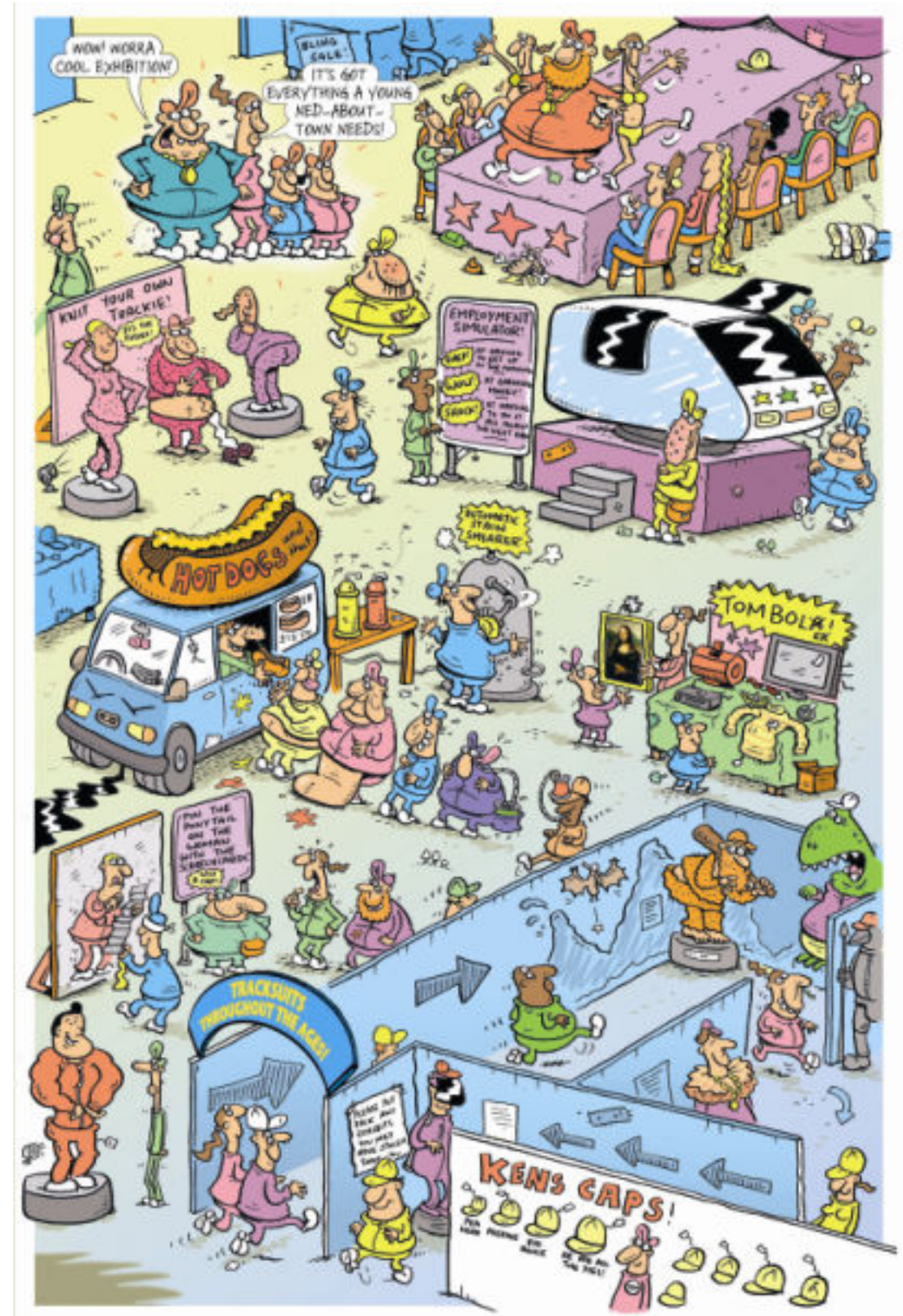

Figure 2. The Neds 2. (The Neds @ D.C. Thompson \& Co. Ltd)

8.4 In The Family Outing (see Neds 2 above) a central attraction of the exhibition displayed in the full-page panel is the 'employment simulator'. This attracts Neds through its advertising: 'GASP! At having to get up in the morning'; WOW! At earning money! SHOCK! At having to do it all again the next day'. Neds leave the simulator shaken and shocked. Here we have an unambiguous demonstration of the distance between Neds and working life and the normative moralities of obligation, deferred gratification and responsibility that accompany it. In the following panels, Ned is enticed to try the 'Trackie 3000' a state-of-the art tracksuit. A feature of the 'Trackie $3000^{\prime}$ is its transformation into an inflatable armchair. Ned is delighted, pictured imagining himself comfortably seated when queuing for his benefit, whilst declaring 'cool! I can sit whenever I've been er, working too hard'. There is a certain 'knowingness' at play here, as his claim of productivity, compounded by the moment of deliberation ('er') is in clear contrast to his imagination, visible to the reader. Ned's lack of employment is here constructed as an individual failing, a knowing and selfchosen dependency. The tracksuit also features mechanical arms that simultaneously hold a pint, burger, toilet roll, TV guide and TV remote - further appealing to Ned's apparent laziness 'III never have to lift a finger again'. Here the constant theme of laziness and lack of productivity is amplified through Ned's selfish focus on bodily gratification and limited taste.

8.5 The behaviour of the Neds amounts to a multiple transgression of the organizing principles of contemporary personhood -a transgression which reinforces the centrality of productivity for 'respectable' selves. Transgression is here made visible not by a visceral disgust, but by a gaze that mocks the Ned's behaviour. What we can see in the Neds is the reproduction of discourses constituting the working class as 'feckless' and dependent (Welshman 2006). Furthermore, Ned and his family are heavily drawn as knowingly deceptive, lazy and, as if the point needed stressing, laughing at attempts to entice them to work.

\section{Space and Dirt}

9.1 The Ned's History strip ends with Ned expressing his pride in the contribution Neds have made to Britain - 'it just goes to show you... Britain wouldn't be what it is today without us neds... makes me proud - REAL PROUD!'. This monologue is spread across three panels. We initially see Ned talking from his 
open window, taking up the whole frame. The penultimate panel pans out to capture Ned's whole house and similar others in a landscape strewn with Ned-made rubbish (upturned litter bins and shopping trolleys). Ned unashamedly declares his pride at a landscape we assume the viewer will associate with shame and immorality. This juxtaposition is extended in the final panel. The scene pans out to show Ned's house in the midst of Scotland similarly littered with stinking pollution radiating from its shores. Here the collective impact of the individual lifestyles of the immoral Neds is presented as a cancerous growth demanding containment and/or intervention.

9.2 Reflecting a now well-established characteristic in the first panel of The Family Outing we see the Neds littering the landscape on a family visit to the 'National Cap and Tracksuit Exhibition' (a 'chav-tastic day out'). There is only one piece of greenery in the story: a single shrub that receives a discarded can kicked by Nedette. Elsewhere a frog swallows Asbo's ejected chewing gum. In the next panel the exhibition hall has a rubbish skip outside against which young 'neds' urinate. Already a clear picture of The Neds is again established as over-determined by litter, excess and pollution. On approaching the exhibition centre, the Neds are accompanied by 'our kinda people' as Ned puts it; in large numbers, all indistinguishable from each other in tracksuits and caps. We are partly reminded of the final panel of $\mathrm{NH}$, we are presented with the Neds as a collective excess - a problematic 'mass', flooding the landscape, which bears historic similarities to racist representations.

9.3 Reiterating the now common theme of deceitfulness and an unwillingness to pay one's due, the family avoids the entrance fee by dressing as pensioners and babies. The exhibition displays 'everything a youngned-about-town-needs', the focus of which are 'trackies', baseball caps and fast food. A line of salivating and overweight Neds, queue up in front of a van for extra large hot dogs. Flies buzz around the sauce dispensers; the van leaks petrol and it and the surrounding environment are splattered with food stains. Here and elsewhere the Ned's slavish devotion to the 'wrong' foods accompanies expulsions and excretions which taint not just the protagonist, but their environment.

9.4 What is striking is the way that white, working-class space is re-presented in these strips. Khatib (2004) draws on Said's (1978) 'imagined geographies' to think of ways that the powerful, make sense of the land and space of Others. She argues that repeated cultural representations of specific spaces create and consolidate 'myths' not only of the physical landscape but 'of the people who inhabit or are linked to it' (2004 :73). The landscapes are clearly those of poverty, but as the characters are seen to be actively littering, urinating and polluting, they are presented as consequences of Neds' own behaviours. In both stories the Ned family quickly convey their belonging to 'their' space helping to fix the Neds as a naturalised part of their landscape (Khatib 2004) Indeed it becomes written on their bodies, as their clothes are as stained as the landscape, and just as proudly claimed and protected (FO).

9.5 There is an explicit concern here that 'neds' threaten the eco-system and welfare system through irresponsible consumption (the litter is mainly that from fast food). There could be an opportunity here to parody consumption more generally, but this is deflected by the repeated association of space, 'neds' and pollution to the extent that the 'neds' come to personify 'filth'. Seale (2006) draws on Mary Douglas's definition of dirt as 'matter out of place', to argue that such a personification secures the exclusion of those who do not 'appropriately' participate in consumer culture, while maintaining 'the ideology of 'aspirationalism' and the 'wider capitalist project' for those who do: as 'out of place' the 'neds' are again depicted as outside the bounds of respectability. Not only are they embedded spatially but they also embody the consequence of engaging in the very practices denied the disciplined body.

9.6 The notion that the Neds are 'matter out of place' speaks directly to the ways in which class distinction work has a keenly spatial dimension. McDowell (2006) observes a repeated spatial 'fixing' of class and space ; not only do reality 'make-over shows' focus on the homes and spaces of their participants ('types' have known and recognisable habitats), but government 'social inclusion' initiatives are often launched from the physical sites of 'excluded' council housing estates (Haylett 2001). McDowell's wider point is that a middle-class belief that their spaces and properties are under threat from an encroaching other creates a certain rigidity of class positions in cities, citing Skeggs point that 'geographical referencing is one of the contemporary shorthand ways of speaking class' (McDowell 2006: 838). Indeed controls such as tagging and curfews ensure that the undesirables are 'corralled' into specific, zoned spaces (McDowell 2006: 839). While disgust may be marshalled to help forge spatial borders, the act of creating distance is undermined by an anxiety that such corralling is not effective and a sense of unease too about the social exclusion that such measures add to and produce.

9.7 Our task in this section was to explore what shape contemporary class representations take. What we draw from this brief illustration following McRobbie, Lawler and others, is that these types of representation may form the basis of distinction work which lies at the heart of contemporary class antagonism, including mockery and disgust. What we see circulating in the The Neds are certain threats to middle-class normative lifestyle projects / ontological security, which pull upon discourses relating to the responsible, disciplined self. Hence, 'neds' are obese, polluting and rejecting of attempts to assimilate them. But classed responses are not only about disgust at bodily excesses which threaten a normative self-image; they are also about other elements which may be harnessed for distinction work: the denigration of the environment, of a benevolent and trusting welfare system, and the all important balance between 'rights and responsibilities'. Yet this work is 'lifted' to the place of the 'funnies' and thus risks escaping critical notice (Lockyer and Pickering 2008). Significantly this denigration of class asserts itself as unaccountable in the guise of 'harmless fun'.

\section{Conclusion}

10.1 We have been encouraged by Savage (2003) and others to unpack the workings of class-distinction work as they are lived out and experienced in the 'everyday'. Taking mockery as a means to think about the motivations and experiences of distinction work, we have taken forward Lawler's (2005) concern to 
make visible middle-class normative, yet we have hesitated to simply graft 'disgust' on to our interpretations of mockery Instead we have suggested here that mockery emerges as the prevailing means of (mainstream media) distinction work because it, after Billig (2005), offers spaces where denigration, expressions of disgust, or those of taste-difference can be communicated within liberal, morally sensitive contexts that are those of normative middle-class. If disgust is central to distinction work, then formulations and expression may be more tentatively expressed through mockery, where is they are deemed appropriate enough to pass class sensibilities, than they gain in confidence, while still allowing the speaker a means of retreat - it's only a joke.

10.2 What could be in our critical grasp here is a softening of Lawler's (2005) and other's thesis of disgust, as it is opened up to acknowledge more varied psychosocial emotions in the work of distinction.

Furthermore, it may point towards a portrayal of class distinction with more fractures and fissures in it, more heterogeneous than wholesale disgust of one monolithic group for another. Vincent and Ball assert that if 'class analyses are to go beyond a blunt middle class / working class dichotomy, we need to consider the behaviour and values of particular class fractions and nuanced similarities and differences between them' (Vincent and Ball 2007: 1062). We would not suggest that mockery is something the middle classes automatically mimic in consuming certain media discourses; the establishment of middle class moral normativity works on all of us in complex psychosocial combinations which to some extent defy categorization. However, the role of mediated discourses of classed identities may have some power in everyday distinction work.

10.3 Thus one recent study interviewed children aged between 8 and 13 years, some from a disadvantaged housing estate, some from a fee-paying independent school (Sutton et al. 2007). The study found that all of the children were eager to be seen as 'average' along a continuum of poverty through to affluence, and consequently defined themselves in terms of what they were not rather than what they were. 'Chav', the English equivalent of 'Ned', was 'used exclusively by the private schoolchildren - not at all by the estate children. Chavs were 'distinguishable because of their outfits of tracksuits, hoods and baseball caps' and were 'common' and 'behaved badly' (12). More specifically chavs were identified as 'children who lived on estates and had parents who were unemployed, with poor parenting skills' (13). That children are using such categories to represent others and distinguish themselves suggests that patterns of mockery towards a socially recognisable 'other' end up constituting structures of feeling along class lines in which the working class are routinely rendered abject and the middle class the hidden norm. We are not amused.

\section{Notes}

${ }^{1}$ Vincent and Ball's (2007) study of middle-class parenting practices similarly claims that the 'enrichment' activities they increasingly take up for the benefit of their children reflect anxieties over losing one's classed status and uncertainty over how to reproduce it.

${ }^{2}$ At the time screened by the BBC and presented by Trinny Woodall and Susannah Constantine

${ }^{3}$ For a more detailed account of Scottish cultural variations on the ned, see Law (2006).

\section{References}

ADAMS, M. and RAISBOROUGH. J. (2008) 'What Can Sociology Say About Fair Trade? Ethical Consumption, Reflexivity and Class', Sociology Vol. 42(6), pp. 1165-1182 [doi:10.1177/0038038508096939]

BEAULIEU, T. (2007) 'Contextual Feminism: Negotiating Feminist Principles and Identity In Context Specific Settings', 2007 International Society of Theoretical Psychology Conference: York University, Toronto: Canada.

BECK, U. AND WILLMS, J. (2004) Conversations with Ulrich Beck. Cambridge: Polity

BOK, L. (2004) The Little Book of Chavs Bath: Crombie Jardine Publishing Limited

BILLIG, M. (2005) Laughter and Ridicule: Towards a Social Critique of Humour. London: Sage

BOURDIEU, P. (1984) Distinction (translated by R. Nice). London: Routledge

BRANNEN, J. and NILSEN, A. (2005) 'Individualisation, Choice and Structure: A Discussion of Current Trends in Sociological Analysis', Sociological Review, Vol. 53, No 3, pp. 412-428. [doi:10.1111/j.1467954X.2005.00559.x]

CARRIER, D. (2000) The Aesthetics of Comics. Pennsylvania: The Pennsylvania State University Press.

COWAN, D. E. (2005) 'Episode 712: South Park, Ridicule and the Constructions of Religious Rivalry', Journal of Religion and Popular Culture, Vol. Summer, No. 10, <http://www.usask.ca/relst/jrpc/art10southpark-print.html>

CROMPTON, R. (2006) 'Class and Family' Sociological Review Vol. 55(4): 658-677 DAVIES, J.P. (2005) 'Maxim Magazine and the Management of Contempt', Journal of Popular Culture, Vol. 38, No. 6, pp. 10111021.

DOBSON, H. (2006) 'Mister Sparkle meets the Yakuza: Depictions of Japan in The Simpsons', Journal of 
Popular Culture, Vol. 39, No. 1, pp. 44-68. [doi:10.1111/j.1540-5931.2006.00203.x]

DOMOSH, M. (2001) 'The 'Women of New York': A Fashionable Moral Geography', Environment and Planning D: Society and Space, Vol. 19, pp. 573-592 [doi:10.1068/d255]

DORFMAN, A. \& MATTELART, A. (2006) 'Introduction: Instructions on How to Become a General in the Disneyland Club' in Durham, M.G. and Kellner, D. (eds.) Media and Cultural Studies: Keyworks. London: Blackwell Publishing

EPSTEIN, D. and STEINBERG, D.L. (1998) 'American Dreamin': Discoursing Liberally on the Oprah Winfrey Show', Women's Studies International Forum, Vol. 21, No. 1, pp. 77-94. [doi:10.1016/S02775395(97)00079-4]

FORD, T.E. and FERGUSON, M.A. (2004) 'Social Consequences of Disparagement Humour: A Prejudiced Norm Theory', Personality and Social Psychology Review, Vol. 8, No. 1, pp. 79-94.

[doi:10.1207/S15327957PSPR0801_4]

GIDDENS, A. (1991) Modernity and Self-Identity. Cambridge: Polity

GIDDENS, A. (1994) 'Living in a Post-Traditional Society', in U. Beck, A. Giddens and S. Lash, Reflexive Modernization, Cambridge: Polity Press, pp. 56-109.

HAYLETT, C. (2001) 'Illegitimate Subjects? : Abject Whites, Neoliberal Modernisation, and Middle-class Multiculturalism'. Environment and Planning D: Society and Space, Vol.19, pp. 351-370.

[doi:10.1068/d237t]

HAYWARD, K. and YAR, M. (2006) The 'Chav' Phenomenon: Consumption, Media And The Construction Of A New Underclass', Crime Media Culture, Vol. 2, No. 1, pp. 9-28. [doi:10.1177/1741659006061708]

HORNE, M. (2006) 'Beano Whips Up A Storm With Neds Cartoon Strip', Times Online, $<\mathrm{http}: / /$ www.timesonline.co.uk/tol/news/uk/scotland/article727225.ece>

JOFFE, H. and STAERKLÉ, C. (2007) The Centrality of the Self-Control Ethos in Western Aspersions Regarding Outgroups: A Social Representational Approach to Stereotype Content', Culture \& Psychology, Vol. 13, No.4, pp. 395-418.

KHATIB, L. (2004) 'The Politics Of Space: The Spatial Manifestations Of Representing Middle Eastern Politics', Visual Politics, Vol. 3, No. 1, pp. 69-90.

LAW, A. (2006) 'Hatred and Respect: The Class Shame of Ned 'Humour" Variant 25, Spring 2006: 28-30. Available at http://www.variant.randomstate.org/pdfs/issue25/issue25.pdf

LAWLER, S. (2005) 'Disgusted Subjects: The Making Of Middle-Class Identities', Sociological Review, Vol. 3, No. 3, pp. 429-446. [doi:10.1111/j.1467-954X.2005.00560.x]

LOCKYER, S. \& PICKERING, M. (2008) 'You Must Be Joking: The Sociological Critique of Humour and Comic Media' Sociology Compass 2/3: 808-820

MCALLISTER, M.P., SEWELL, JR. E.H. and GORDON, I . (editors) (2001) Comics and Ideology. New York: Peter Lang.

MCDOWELL. L. (2006) 'Reconfigurations of Gender And Class Relations: Class Differences, Class Condescension And The Changing Place Of Class Relations', Antipode, Vol, 38, No. 4, pp. 825-850.

MCROBBIE. A. (2004) 'Notes On 'What Not To Wear' And Post-Feminist Symbolic Violence', Sociological Review, Vol. 52, No. 2, pp. 99-109.

MILLER, W. (1997) The Anatomy of Disgust. Harvard University Press: Cambridge: MA.

MITCHELL, D. (2005) 'Producing Containment: The Rhetorical Construction Of Difference In Will And Grace', Journal of Popular Culture,Vol.38, No.6. pp. 1050-1068. [doi:10.1111/j.1540-5931.2005.00175.x]

NAYAK, A. (2006) 'Displaced Masculinities: Chavs, Youth and Class in the Post-Industrial City', Sociology, Vol. 40, No. 5. pp.813-831. [doi:10.1177/0038038506067508]

PILRIG, K. and McGLINCHY, K. (2005) Nedworld Edinburgh: Black \& White Publishing

REAY, D. (2007) 'Unruly Places: Inner-city Comprehensives, Middle-Class Imaginaries and Working-class Children' Urban Studies Vol 44 no 7, 1191-1203. [doi:10.1080/00420980701302965]

REAY, D. (2006) "I'm not seen as one of the clever children': Consulting primary school pupils about the social conditions of learning' Education Review vol 58 no 2, 171-181. [doi:10.1080/00131910600584066]

REAY, D., HOLLINGWORTH, S., WILLIAMS, K., CROZIER, G., JAMIESON, F., JAMES, D. and BEEDELL, P. (2007) 'A Darker Shade of Pale?' Whiteness, the Middle Classes and Multi-Ethnic Inner City Schooling', Sociology, Vol.41. No.6, pp. 1041-1060. [doi:10.1177/0038038507082314]

ROSE, N. (1990) Governing the Soul: the Shaping of the Private Self. London: Routledge. 
ROZIN. P. (1997) 'Moralization', in A, Brandt and P. Rozin (editors) Morality and Health. London: Routledge. SANDERS. T. (2004) 'Controllable Laughter: Managing Sex Work Through Humour', Sociology, Vol. 38, No. 2, pp. 273-292.

SAVAGE, M. (2003) 'Review Essay: A New Class Paradigm', British Journal of Sociology of Education, Vol. 24, No. 4, pp. 535-541. [doi:10.1080/01425690301920]

SAVAGE, M., BAGNALL, G. and LONGHURST, B. (2001) 'Ordinary, Ambivalent and Defensive: Class Identities in the Northwest of England', Sociology, Vol. 35, No. 4, pp. 875-892.

[doi:10.1177/0038038501035004005]

SAYER, A. (2002) 'What Are You Worth?: Why Class Is An Embarrassing Subject', Sociological Research Online, Vol. 7, No.3, <http://www.socresonline.org.uk/7/3/sayer.html>

SAYER, A. (2005) 'Class, Moral Worth And Recognition', Sociology, Vol. 39, No. 5, pp.947-964. [doi:10.1177/0038038505058376]

SEALE, K. (2006) 'Location ,Location: Situating Bondi's 'Rubbish House', M/C Journal, Vol 9, No. 5, <http://www.journal.media-culture.org.au/0610/07-seale.php>

SKEGGS, B. (1997) Formations of Class and Gender. London: Routledge

SKEGGS, B. (2004) Class, Self, Culture. London: Routledge.

SKEGGS, B. (2005) The Making of Class and Gender through Visualizing Moral Subject Formation', Sociology Vol. 39(5): 965-982 [doi:10.1177/0038038505058381]

SPENCER, B. (2006) 'Beano Gets Asbo Over Neds', Daily Record, 6 February, $<$ http://www. dailyrecord.co.uk/lifestyle/health-

fitness $/ \mathrm{tm} \_$objectid=16670495\& method=full\&siteid=66633\& headline=beano-gets-asbo-over-neds-name_page.html>

STAPLETON, P. (2007) Chav. Brighton: Bedsit Press

STOTT, A. (2005) Comedy. London: Routledge.

SUTTON, L., SMITH, N., DEARDEN, C. and MIDDLETON, S. (2007) A Child's Eye View Of Social Difference. York: Joseph Rowntree Foundation.

SYNDER, E, E. (1997) 'Teaching Sociology Of Sport: Using Comic Strips', Teaching Sociology, Vol.25. No. 3, pp. 239-243. [doi:10.2307/1319401]

TYLER, I. (2006) 'Chav Scum: The Filthy Politics Of Social Class In Contemporary Britain', M/C Journal, Vol. 9, No. 5, <http://www.journal.media-culture.org.au/0610/09-tyler.php>

VALENTINE, J. (1998) 'Naming the Other: Power, Politeness and the Inflation of Euphemisms', Sociological Research Online, Vol. 3, No.4, <http://www.socresonline.org.uk/3/4/7.html>

VINCENT, C. and BALL, S.J. (2007) 'Making Up' the Middle-Class Child: Families, Activities and Class Dispositions', Sociology, Vol. 41, No. 6, pp.1061-1077 [doi:10.1177/0038038507082315]

WELSHMAN, J. (2006) Underclass: A History of the Excluded: 1880-2000. London: Hambledon Continuum. WILLIAMS, J. (1994) Comics: A tool for subversion? Journal of Criminal Justice and Popular Culture 2(6): 129-146. 